\title{
Impact Response of Multi-Grooved Square Column
}

\author{
Amir Radzi Ab Ghani ${ }^{1}$, Chong Siak Kee ${ }^{2}$, Mohd Zaid Othman ${ }^{2}$, Md Fuad Shah Koslan ${ }^{3,4}$ \& Ahmad Mujahid \\ Ahmad Zaidi ${ }^{3,5}$ \\ ${ }^{1}$ Faculty of Mechanical Engineering, University Technology MARA, Shah Alam, Malaysia \\ ${ }^{2}$ Department of Engineering Design \& Manufacturing, Faculty of Engineering, University Malaya, Kuala Lumpur, \\ Malaysia \\ ${ }^{3}$ Department of Mechanical Engineering, Faculty of Engineering, National Defence University of Malaysia, \\ Kuala Lumpur, Malaysia \\ ${ }^{4}$ Royal Malaysian Air Force, Ministry of Defence, Kuala Lumpur, Malaysia \\ ${ }^{5}$ International College of Automotive, Pekan Pahang, Malaysia \\ Correspondence: Amir Radzi Ab Ghani, Faculty of Mechanical Engineering, University Technology MARA, \\ Shah Alam, Malaysia. Tel: 60-12-356-4447. E-mail: amirradzi@gmail.com
}

Received: July 22, 2013 Accepted: October 4, $2013 \quad$ Online Published: October 17, 2013

doi:10.5539/mas.v7n11p12 URL: http://dx.doi.org/10.5539/mas.v7n11p12

\begin{abstract}
This work aims to determine the response and impact energy absorbing capability of the square hollow section (SHS) column with U-shape grooves, subjected to dynamic mid span loading. Geometrical parametric study i.e. width and depth of the grooves and spacing between grooves was carried out using non-linear explicit finite element package ABAQUS. Comparison between plain SHS column with grooved SHS column in terms of initial peak force (IPF), specific energy absorption (SEA) and crush force efficiency (CFE) was carried out. It was found that the depth and width of the groove and spacing between grooves have significant effect on the impact response of SHS column. The grooved column has a higher SEA, shorter crushing distance but slightly lower CFE as compared to the plain column. This would make the grooved column a better option when designing for side intrusion protection.
\end{abstract}

Keywords: SHS column, impact response, non-linear explicit finite element

\section{Introduction}

Global accident statistic shows that side impacts accounted for approximately $30 \%$ of all impacts and $35 \%$ of total fatalities as reported by German in Depth Accident Study (GIDAS) and National Automotive Sampling System (NASS). This shows that side impact crash is frequent and generally dangerous to car occupants. There is considerably less crash zone for absorbing the impact energy as compared to vehicle's frontal and rear structure. As a result, occupants sitting in the crash zone will be exposed to severe injuries and even death.

Door panel intrusion is the most significant contributor in occupant injuries where it can increase the risk of chest, abdominal and pelvis injuries (Cheon, Lee, \& Jeong, 1997). The stiffness, geometry and intrusion of door panel in side impact may result in specific injuries patterns. In order to avoid the side door intrusion into the passenger car compartment, automotive manufactures purposely reinforce the side door with intrusion (door) beam. These beams provide the occupants with improved level of safety. The side impact beam is normally fitted into car door at the lower section of the door frame and is designed to absorb the impact energy while at the same time, minimize the penetration into the passenger compartment during side crash incident.

Hollow section beam (thin-walled columns) has a high energy-absorption capability. Such beams are mostly used in truss and frame structures and are able to absorb substantial amount of crash energy during impact. Load path and maximum resisting load of the door are the major factors in material and design consideration. Mechanical properties, shape, size and thickness of door components will greatly influence the load carrying capacity and intrusion of the side door structure. Proper selection of these variables is required to provide the most efficient design (Farley \& Jones, 1992). Aluminium alloy has gained increased popularity as a material of choice for modern car structure. Galib and Limam (2004) evaluated its energy absorption capabilities to ensure that the integrity of the passenger compartment is maintained and minimal deceleration is transferred to the occupants 
during impact.

The first comprehensive study of the deep bending collapse of prismatic member was made by Kecman (1983). The bending collapse behavior of rectangular and square sections was studied experimentally and theoretical model was developed based on experimental observations. Simple failure mechanisms involving stationary and moving plastic hinge lines were proposed in the analysis, and the moment-rotation characteristic was calculated in the post-failure range.

Santosa et al. (2001) studied the effect of foam-filling on the bending crush resistance of a thin-walled beam through quasi-static three point bending simulations and experiments. It was found that the presence of the foam filler resisted the inward sectional collapse at the compressive flange and changes the crushing mode from a single stationary fold to a multiple propagating folds and therefore prevents the drop in the load carrying capacity due to local sectional collapse. Zarei and Kroger (2008) studied the dynamic bending behavior of empty and foam-filled aluminum beams by using the explicit finite element code LS-Dyna. Crashworthiness optimization procedure was applied to maximize the specific energy absorption of the aluminum beams. Good agreements between experiment and simulation results were observed and therefore further investigations were done numerically.

Side impact beam can be made up from a wide range of hollow structures such as rectangular, cylindrical and trapezoidal as well as honeycomb. Square hollow structure is chosen in this study as it is predominantly used in modern automotive structures due to its ease of fabrication, versatility and superior impact energy absorption capability. The addition of U-shaped grooves longitudinally to two opposing sides of the square hollow section aims to enhance the impact performance.

\section{Impact Performance Indices}

Crashworthiness of a structure is defined as the ability to absorb the impact energy and thereby bringing the vehicle to rest without the occupant being subjected to high or sudden deceleration. It is expressed in term of specific energy absorption (SEA), $E_{s}$ which is the ratio of energy absorbed to the unit mass of the material.

$$
E_{s}=\frac{W}{V \rho}
$$

where $W=$ total energy absorbed

$V=$ volume of material

$\rho=$ density of material

Crush force efficiency (CFE), $\eta_{c}$ is normally defined as the ratio of mean load, $\mathrm{F}_{\text {mean }}$ to initial peak force, $\mathrm{F}_{\text {peak }}$. It is useful to measure the performance of an absorber where an ideal absorber is said to exhibit a crush force efficiency of $100 \%$ which is difficult to achieve in actual.

$$
\eta_{C}=\frac{F_{\text {mean }}}{F_{\text {peak }}}
$$

The initial peak force is also of equal importance as this force tends to be very high and may cause severe injury to the occupant. In some structures, trigger mechanism is added to the existing system as a mean to reduce this high initial peak force.

\section{Finite Element Modeling}

The plain and U-grooved square columns were modeled in ABAQUS as 3D deformable shells. The roller supports and impactor were modeled as discrete rigid bodies. Figure 1 shows the assembled finite element model. The optimum number of elements was chosen after performing mesh discretization method, which was similar to a mesh sizing method implemented by Md Fuad et al. (2013). About 5500 4-noded linear quadrilateral explicit shell element of type S4R were used for the plain column while about 6000 to 9000 elements were used for the grooved columns. For the rigid bodies, about 2800 4-noded rigid linear quadrilateral elements of type R3D4 were used. 


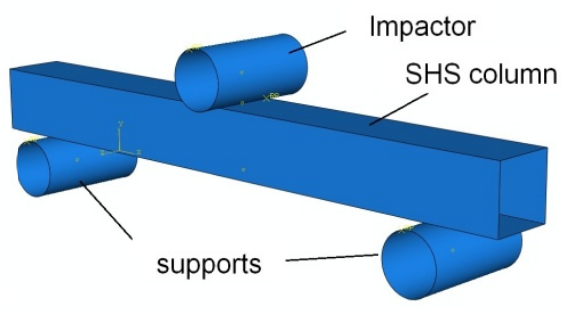

Figure 1. Assembly of finite element models

The slot geometric parameters and dimension are given in Figure 2. Selection of test specimen dimensions is usually dictated by the test rig load and space capacity. Therefore, a square column with overall length (L) of 550 $\mathrm{mm}$, width (D) of $55 \mathrm{~mm}$ and thickness (T) ranging from 1 to $3 \mathrm{~mm}$ were used. For the U-grooved column, width (W) of groove ranging from 10 to $50 \mathrm{~mm}$ and height $(\mathrm{H})$ of groove ranging from 3 to $15 \mathrm{~mm}$ were used. For the 2-grooved column, spacing (S) between grooves ranging from $5 \mathrm{~mm}$ to $25 \mathrm{~mm}$ was used.

Calibration of simulation with previous experimental results was performed to ensure confidence and validity of the proposed analysis technique. Material properties were assigned to the model. The columns were made from aluminum alloy AA6060-T5 (Zarei \& Kroger, 2008). They follow the material relationship of elastic-plastic linear strain hardening. Detail material properties of the columns are given in Table 1.

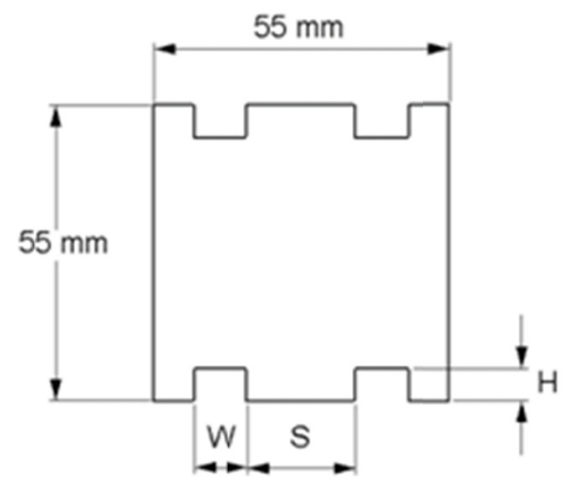

Figure 2. Slot geometric parameters

Table 1. Properties of Aluminium Alloy AA6060-T5 (Zarei \& Kroger, 2008)

\begin{tabular}{|c|c|c|}
\hline Density $\left(\mathrm{kg} / \mathrm{m}^{3}\right)$ & \multicolumn{2}{|c|}{2700} \\
\hline Ultimate Stress (MPa) & \multicolumn{2}{|c|}{264} \\
\hline Young's Modulus (GPa) & \multicolumn{2}{|c|}{68.9} \\
\hline Poisson's Ratio & \multicolumn{2}{|c|}{0.33} \\
\hline \multirow[t]{2}{*}{ Rate Dependent Coefficients } & Multiplier (D) & Exponent (q) \\
\hline & $6500 \mathrm{~s}^{-1}$ & 4 \\
\hline \multirow[t]{7}{*}{$\begin{array}{llr}\text { Data obtained } & \text { from } & \text { true } \\
\text { stress-strain } & \text { curve } & \text { of } \\
\text { AA6060 T5 } & & \end{array}$} & Yield Stress (MPa) & Plastic Strain \\
\hline & 180.0 & 0.000 \\
\hline & 190.0 & 0.005 \\
\hline & 205.0 & 0.010 \\
\hline & 210.0 & 0.015 \\
\hline & 218.0 & 0.020 \\
\hline & 220.0 & 0.025 \\
\hline
\end{tabular}


A dynamic explicit solver ABAQUS EXPLICIT was used. Time durations ranging from $0.02 \mathrm{~s}$ to $0.05 \mathrm{~s}$ were specified depending on the column configuration. The contact behavior between the column, support and impactor during collision was set up under the interaction module. The contact property consisted of tangential behavior, which used a 'penalty' friction formulation with a coefficient of 0.2 . The normal behaviour use the 'hard contact' formulation to allow separation after contact. A general dynamic (explicit) contact was utilized where all the contact surfaces are automatically identified by the system.

Boundary conditions and impact speeds were specified in the load module. For the impactor, the boundary conditions were $\mathrm{V} 1=\mathrm{V} 3=\mathrm{VR} 1=\mathrm{VR} 2=\mathrm{VR} 3=0$, which implies that it could only move in the vertical $\mathrm{y}$-direction. The supports were fully constrained. Movement of the column in the $\mathrm{x}$ - and $\mathrm{z}$-directions was restrained by the friction between the column and the supports. Impactor velocity of $14 \mathrm{~m} / \mathrm{s}$ was specified in the predefined field and the impactor mass of $5 \mathrm{~kg}$ was inputed as inertia in the engineering features. The simulation test parameters for calibration are given in Table 2 .

Table 2. Simulation Test Parameters for Calibration (Zarei \& Kroger, 2008)

\begin{tabular}{cc}
\hline Material & Aluminum Alloy 6060-T5 \\
\hline Density & $2700 \mathrm{~kg} / \mathrm{m}^{3}$ \\
Yield Stress, $\sigma_{0.2}$ & $231 \mathrm{MPa}$ \\
Ultimate Stress, $\sigma_{\mathrm{uts}}$ & $254 \mathrm{MPa}$ \\
Height x Width x Length & $55 \mathrm{~mm} \times 55 \mathrm{~mm} \times 550 \mathrm{~mm}$ \\
Thickness & $2 \mathrm{~mm}$ \\
Impact Mass & $45 \mathrm{~kg}$ \\
Impact Speed & $4.4 \mathrm{~m} / \mathrm{s}$ \\
Contact Friction Coefficient, $\mu$ & 0.2 \\
\hline
\end{tabular}

\section{Results and Discussion}

\subsection{Simulation Validation}

Figure 3(a) shows the beam bending failure mode from experiment and Figure 3(b) is from validation simulation test. Figure 4 shows the experimental and simulation force-displacement curves. The simulation result compared favorably with the experimental result, hence validating the accuracy of the simulation technique and ABAQUS explicit code. The simulation was able to predict fairly accurately the peak force, the mean force and the formation of folds.

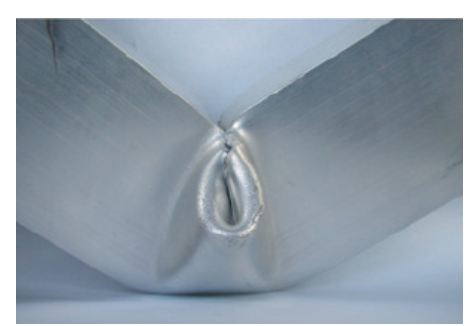

(a)

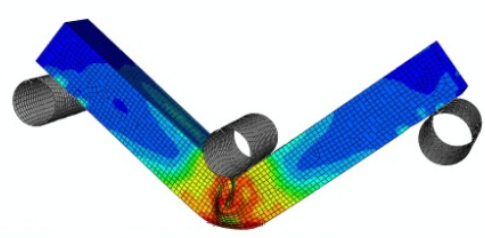

(b)

Figure 3. Beam bending failure modes from (a) experiment (Zarei \& Kroger 2008); (b) simulation 


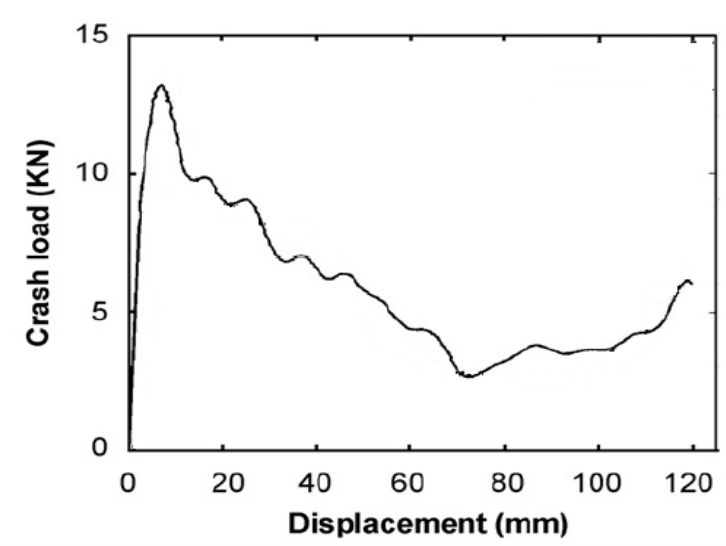

(a)

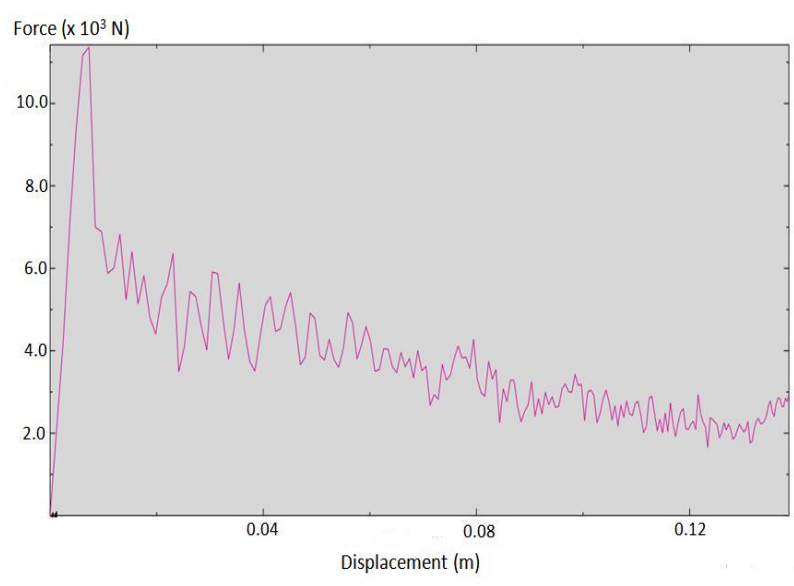

(b)

Figure 4. Force-displacement curves for (a) experimental (Zarei \& Kroger 2008); (b) simulation

\subsection{Comparison Between Plain and 1-Grooved SHS Columns}

Figure 5 shows the force-displacement curves for plain SHS column and U-grooved SHS columns with equal thickness of $1 \mathrm{~mm}$. The grooved column has a groove width of $30 \mathrm{~mm}$ and groove height of $3 \mathrm{~mm}$. It can be seen that the grooved column has the higher IPF and shorter crushing distance as compared to the plain column. The grooved column also has higher and more uniform mean force. The plain column shows a less uniform mean force which gradually decrease towards halfway of the crushing distant and rose again towards the end. In short, grooved column would have better energy absorption while the plain column would have better injury protection due to the lower forces transmitted to the occupants.

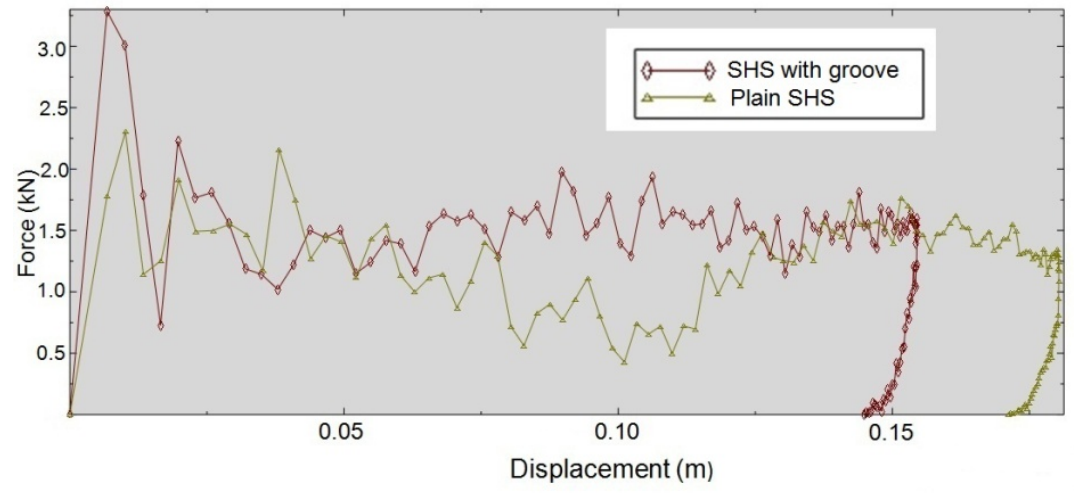

Figure 5. Force-displacement curves of plain and 1-grooved SHS column with impact speed of $14 \mathrm{~m} / \mathrm{s}$ and impact mass of $5 \mathrm{~kg}$

Figure 6 shows that the addition of a single groove on both opposing faces of the SHS column has managed to considerably increase the initial peak force. Figure 7 shows the specific energy absorption (SEA) of plain and U-grooved SHS column and Figure 8 shows the crush force efficiency (CFE). It can be seen that the grooved column has a much higher SEA as compared to the plain column. This could be due to the additional faces of the grooves opposing and absorbing the impact energy. The grooves cause the formation of more hinge lines hence further increasing the plastic dissipation energy due to plastic bending. Also, due to increased resistance of bending provided by the additional groove faces, the grooved column has higher IPF, which resulted in slightly lower CFE as compared to the plain column. In the context of side intrusion protection, the grooved column would be the more suitable choice as it has higher SEA and lower crushing distance despite the slightly lower CFE and high initial force. However, this groove configuration has yet to be optimized. It may be possible to obtain high SEA and CFE, and low crushing distance by further optimizing the groove configuration, which was attempted in the following sections. 


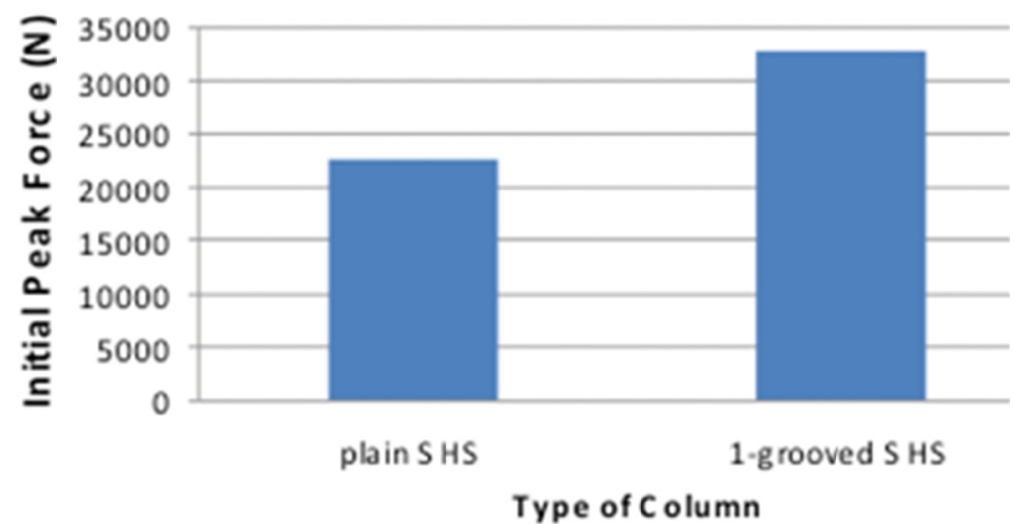

Figure 6. Initial peak force of plain and 1-grooved SHS columns with impact speed of $14 \mathrm{~m} / \mathrm{s}$ and impact mass of 5 $\mathrm{kg}$

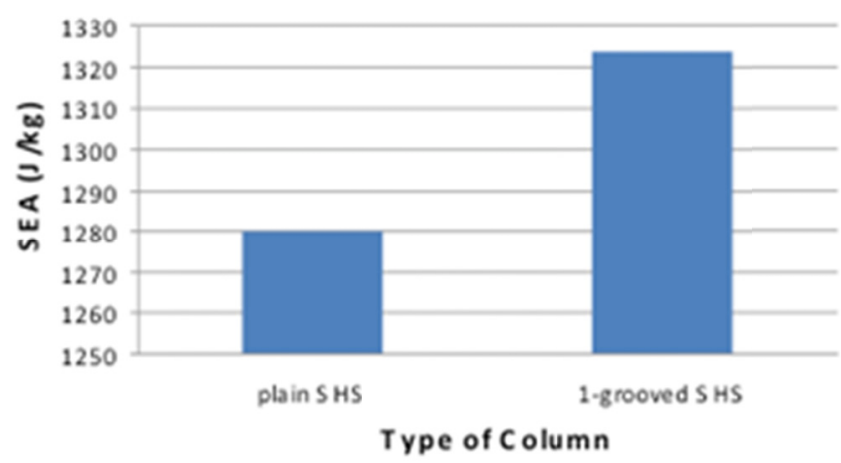

Figure 7. Specific energy absorption (SEA) of plain and 1-grooved SHS columns with impact speed of $14 \mathrm{~m} / \mathrm{s}$ and impact mass of $5 \mathrm{~kg}$

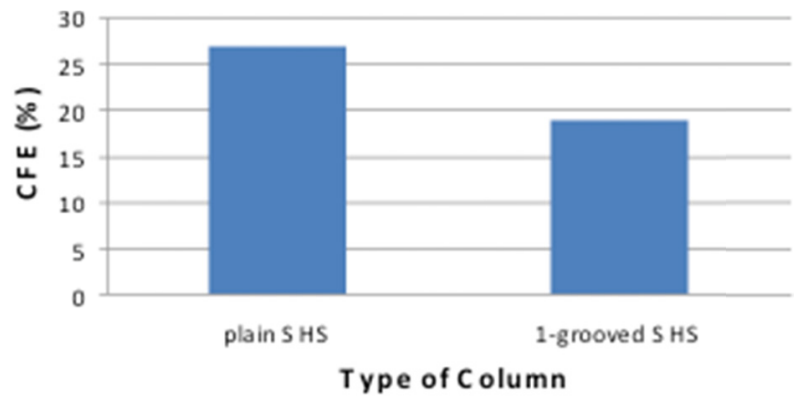

Figure 8. Crush force efficiency (CFE) of plain and 1-grooved SHS columns with impact speed of $14 \mathrm{~m} / \mathrm{s}$ and impact mass of $14 \mathrm{~kg}$

\subsection{Effect of Thickness on 1-Grooved SHS Column With Groove Depth of $6 \mathrm{~mm}$ and Groove Width of $10 \mathrm{~mm}$}

Figure 9 shows the force-displacement curves of 1-grooved SHS column with different thicknesses. As expected, the crushing distances increased with lower thickness while the forces increased with higher thickness. This is to satisfy the energy conservation principles where the kinetic energy is dissipated by plastic deformation of column, which is given by the area under the force-displacement curves. 


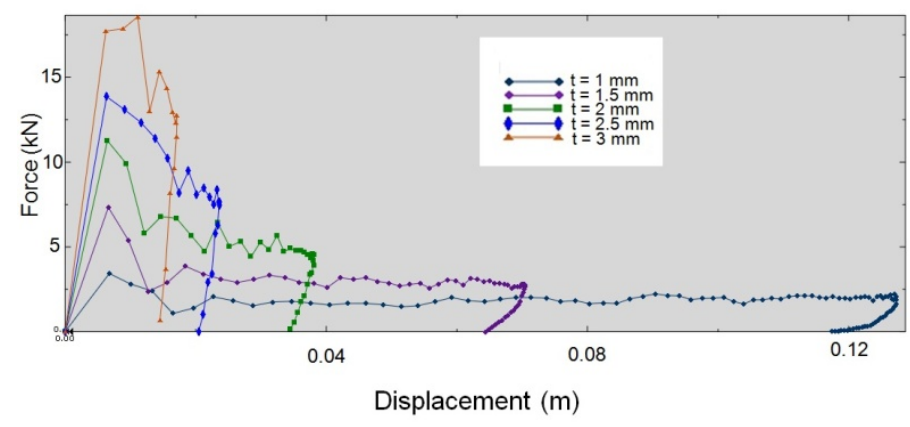

Figure 9. Force-displacement curves of 1-grooved SHS column with impact speed of $14 \mathrm{~m} / \mathrm{s}$, mass of $5 \mathrm{~kg}$ and different thicknesses

Figure 10 shows the deformation modes of 1-grooved SHS columns with different thicknesses. It can be seen that for the smaller thickness column, crushing of the grooves and folding of the side faces were prominent. For the thicker columns, failure was limited to flattening of the grooves.

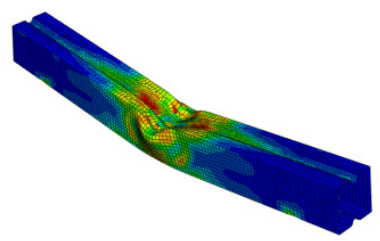

$\mathrm{t}=1 \mathrm{~mm}$

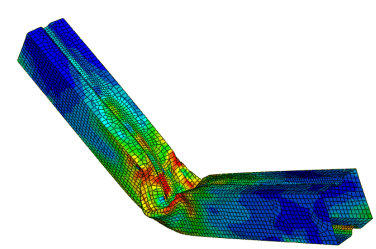

$\mathrm{t}=2 \mathrm{~mm}$

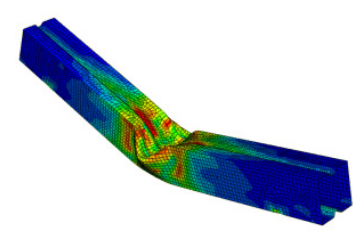

$\mathrm{t}=1.5 \mathrm{~mm}$

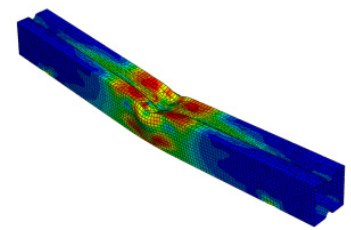

$\mathrm{t}=2.5 \mathrm{~mm}$

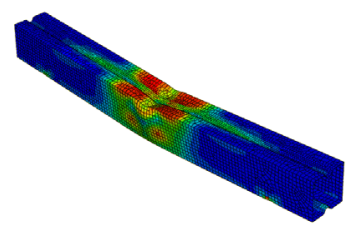

$\mathrm{t}=3 \mathrm{~mm}$

Figure 10. Deformed shapes of 1-grooved SHS column with impact speed of $14 \mathrm{~m} / \mathrm{s}$, impact mass of $5 \mathrm{~kg}$ and different thicknesses

Figure 11 shows that increasing the column thickness will result in an increase in the IPF. The thickness has direct effect on the bending stiffness of the column, hence the higher force required. Figure 12 shows that the SEA decreased with increasing thickness. Increasing the thickness which will affect the volume and mass of the column, does not proportionally increased the energy absorbed. The high IPF can cause injury to occupant but the small crushing distance can be advantageous in specific condition such as prevention of side intrusion. Figure 13 shows that the CFE also decreased with increasing thickness. The low thickness columns have lower IPFs followed by more uniform mean forces. Note that the three performance indicators i.e. the IPF, SEA and CFE are contradicting each other and therefore groove design need to be optimized for the given requirement. 


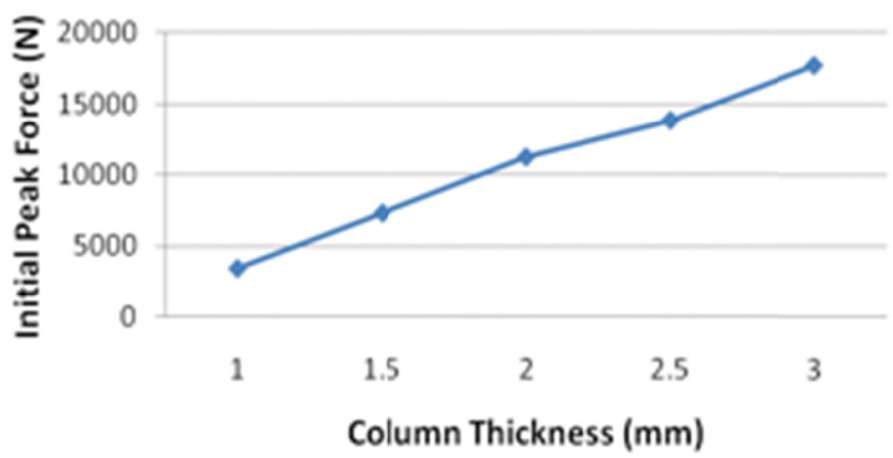

Figure 11. Initial peak force of 1-grooved SHS columns with impact speed of $14 \mathrm{~m} / \mathrm{s}$, impact mass of $14 \mathrm{~kg}$ and different thicknesses

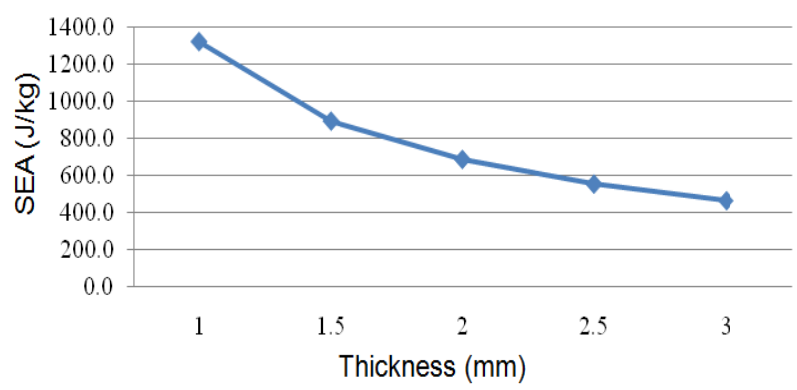

Figure 12. Specific energy absorption (SEA) of 1-grooved SHS columns withimpact speed of $14 \mathrm{~m} / \mathrm{s}$, impact mass of $14 \mathrm{~kg}$ and different thicknesses

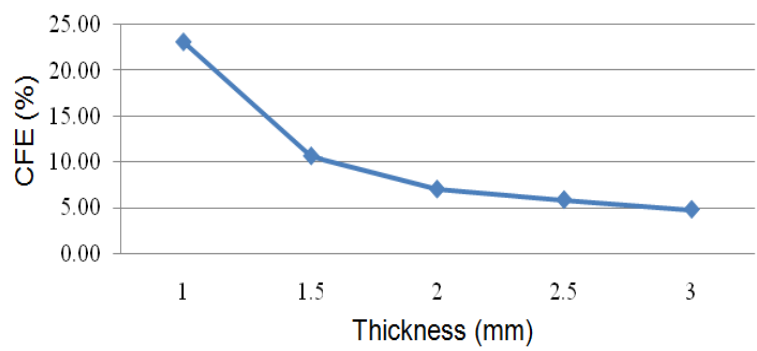

Figure 13. Crush force efficiency (CFE) of 1-grooved SHS columns with impact speed of $14 \mathrm{~m} / \mathrm{s}$, impact mass of $14 \mathrm{~kg}$ and different thicknesses

\subsection{Effect of Groove Depth on 1-Grooved SHS Column With Thickness of $1 \mathrm{~mm}$ and Groove Width of $25 \mathrm{~mm}$}

Figure 14 shows the force-displacement curves for U-grooved SHS columns with different groove depths. It can be seen that the column with groove depth of $15 \mathrm{~mm}$ exhibited the highest IPF and longest crushing distance. Columns with groove depths of $12 \mathrm{~mm}$ and $9 \mathrm{~mm}$ showed similar characteristics. Columns with groove depths of 3 $\mathrm{mm}$ and $6 \mathrm{~mm}$ exhibit more favorable characteristics, which have lower initial peak forces and also shorter crushing distance. This would imply that further increasing the groove depth will reduce the impact performance of the column. Figure 15 shows the deformed shapes of the U-grooved SHS columns with different groove depths. Column with groove depth of $3 \mathrm{~mm}$ exhibited prominent deformation in the vicinity of the crush region with the upper face following the shape of the impactor. The side faces seemed to have more rounded shapes as compared to the triangular faces of the Kecman model. Columns with groove depths of $9 \mathrm{~mm}$ and more exhibited even spectacular deformations. Failure regions in the top and side faces are extended towards the ends of the column. There is a prominent fold in the center of the column with the side faces jamming together at the top face forming a loop. 


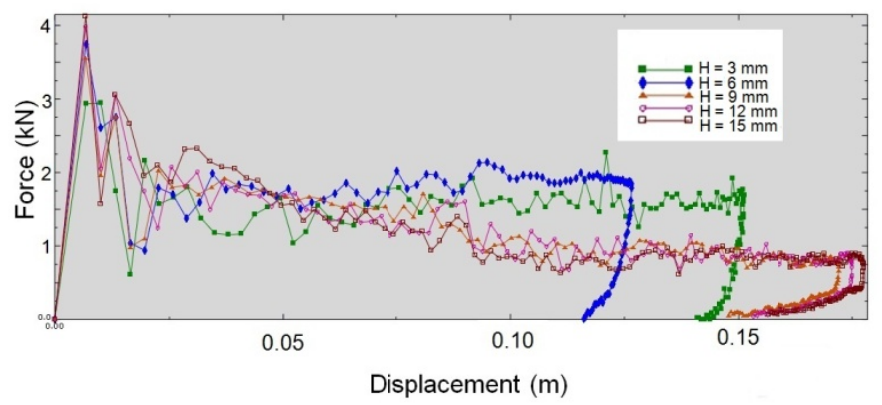

Figure 14. Force-displacement curves of 1-grooved SHS column with different groove depths, impact speed of 14 $\mathrm{m} / \mathrm{s}$ and impact mass of $5 \mathrm{~kg}$
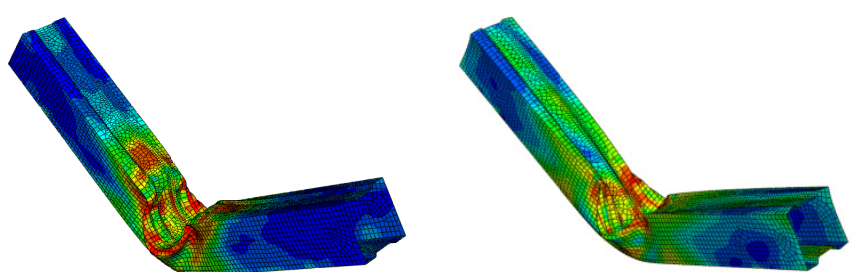

$\mathrm{d}=3 \mathrm{~mm}$

$\mathrm{d}=6 \mathrm{~mm}$
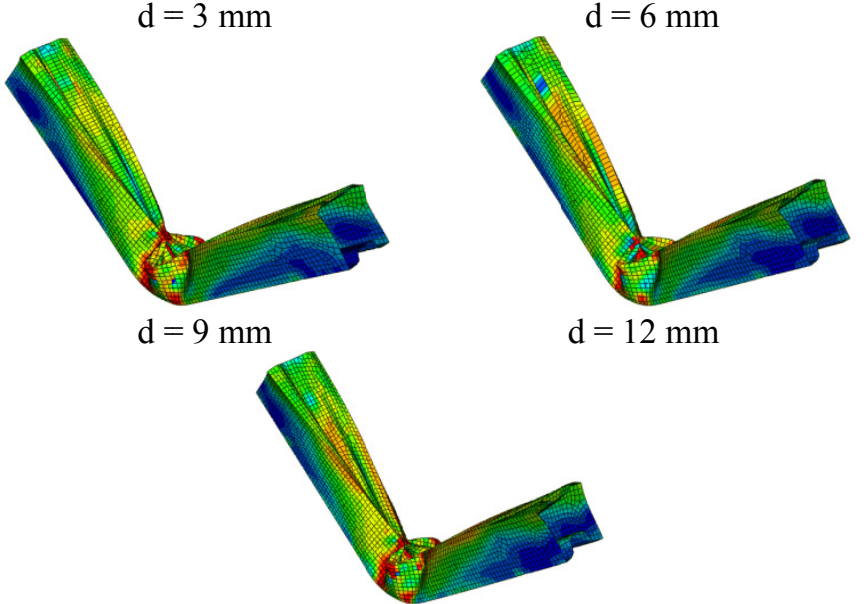

$\mathrm{d}=15 \mathrm{~mm}$

Figure 15. Deformed shapes of 1-grooved SHS column with impact speed of $14 \mathrm{~m} / \mathrm{s}$ and impact mass of $5 \mathrm{~kg}$

Figure 16 shows that by increasing the groove depth increase the IPF. Groove depths of $3 \mathrm{~mm}$ and $6 \mathrm{~mm}$ have similar IPFs. There was a substantial increase in IPF with groove depths of $9 \mathrm{~mm}$ and $12 \mathrm{~mm}$. For groove depths of $9 \mathrm{~mm}$ and more, the vertical faces of the grooves acted as stiffeners that required additional force to bend them.

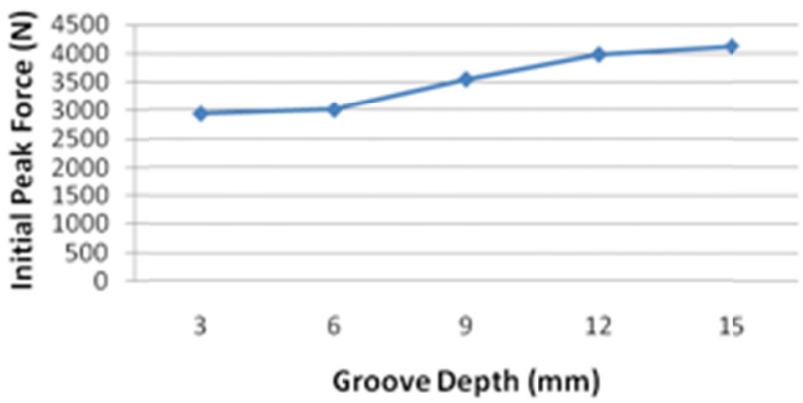

Figure 16. Initial peak force of 1-grooved SHS column with different groove depths, impact speed of $14 \mathrm{~m} / \mathrm{s}$ and impact mass of $5 \mathrm{~kg}$ 
Figure 17 shows the specific energy absorption (SEA) of U-grooved SHS column with different groove depth and Figure 18 shows the crush force efficiency (CFE). Increasing the groove depth tends to decrease the SEA. There is a sudden drop of SEA for groove depth of more than $6 \mathrm{~mm}$. Groove depth of $3 \mathrm{~mm}$ gives the highest CFE. Further increasing the groove depth will gradually decrease the CFE. In short, further increasing the groove depth will have detrimental effect on the SEA and CFE of the columns.

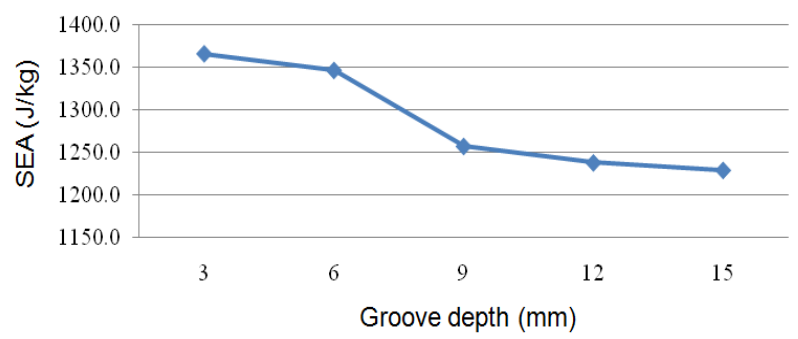

Figure 17. Specific energy absorption (SEA) of 1-grooved SHS column with different groove depths, impact speed of $14 \mathrm{~m} / \mathrm{s}$ and impact mass of $5 \mathrm{~kg}$

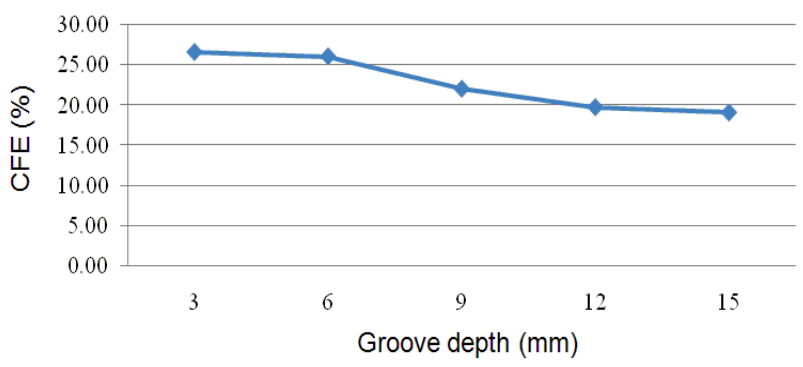

Figure 18. Crush force efficiency (CFE) of 1-grooved SHS column with different groove depths, impact speed of $14 \mathrm{~m} / \mathrm{s}$ and impact mass of $5 \mathrm{~kg}$

\subsection{Effect of Groove Width on 1-Grooved SHS Column With Thickness of $1 \mathrm{~mm}$ and Groove Depth of $6 \mathrm{~mm}$}

Figure 19 shows the force-displacement curves for U-grooved SHS columns with different groove widths. It can be seen that the column with groove width of $30 \mathrm{~mm}$ exhibited the highest initial peak force and shortest crushing distance. Columns with groove widths of $10 \mathrm{~mm}$ and $20 \mathrm{~mm}$ showed more favorable characteristics with lower initial peak forces, high mean forces and short crushing distances. Columns with groove width of $40 \mathrm{~mm}$ and 50 $\mathrm{mm}$ have high initial peak forces, low mean forces and long crushing distances which make them less efficient as energy absorber. These imply that further increasing the groove width will reduce the impact performance of the column. Figure 20 shows the deformed shapes of the U-grooved SHS columns with different groove widths. Similarly, column with groove width of $10 \mathrm{~mm}$ exhibited prominent deformation in the vicinity of the crush region with the upper face following the shape of the impactor. The side faces approximated the triangular faces of the Kecman (1983) model. Further increasing the groove width resulted in highly localized deformation in the middle section with the folding faces having more rounded edges.

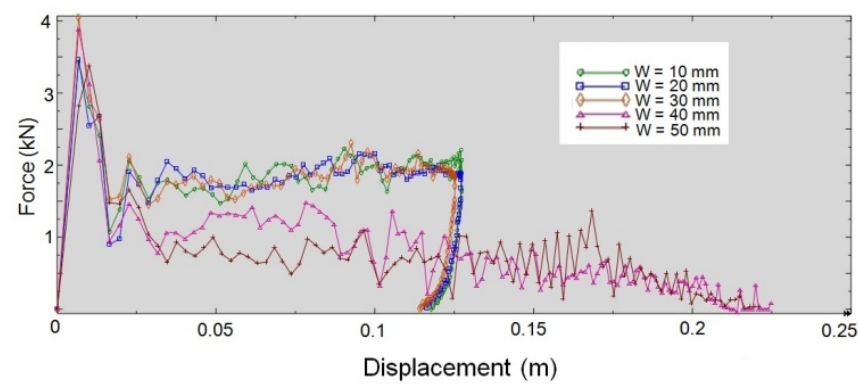

Figure 19. Force-displacement curves of 1-grooved SHS column with different groove widths, impact speed of 14 $\mathrm{m} / \mathrm{s}$ and impact mass of $5 \mathrm{~kg}$ 


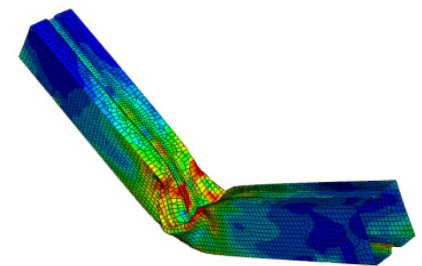

$\mathrm{w}=10 \mathrm{~mm}$

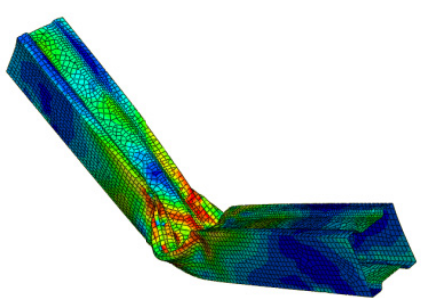

$\mathrm{w}=30 \mathrm{~mm}$

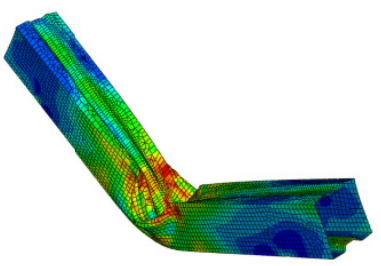

$\mathrm{w}=20 \mathrm{~mm}$

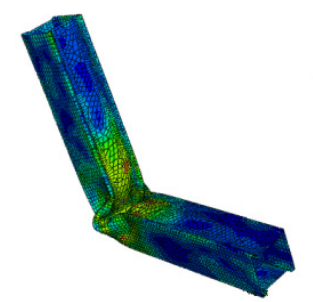

$\mathrm{w}=40 \mathrm{~mm}$

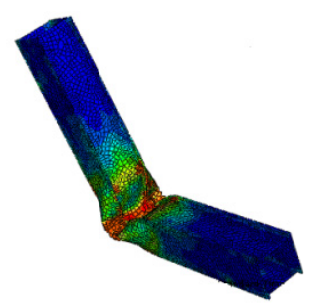

$\mathrm{W}=50 \mathrm{~mm}$

Figure 20. Deformed shapes of 1-grooved SHS column with impact speed of $14 \mathrm{~m} / \mathrm{s}$ and impact mass of $5 \mathrm{~kg}$

Figure 21 shows that groove width of more than $20 \mathrm{~mm}$ resulted in substantial increase in IPF. Further increasing the width to $50 \mathrm{~mm}$ reduced the IPF. Figure 22 shows the specific energy absorption (SEA) of U-grooved SHS column with different groove width and Figure 23 shows the crush force efficiency (CFE). Increasing the groove width tends to decrease the SEA. There is a gradual drop of SEA for groove width of more than $30 \mathrm{~mm}$. Groove widths of $10 \mathrm{~mm}$ and $20 \mathrm{~mm}$ give the highest CFE. Further increasing the groove width gradually decreases the CFE. In short, further increasing the groove width will also have detrimental effect on the SEA and CFE of the columns.

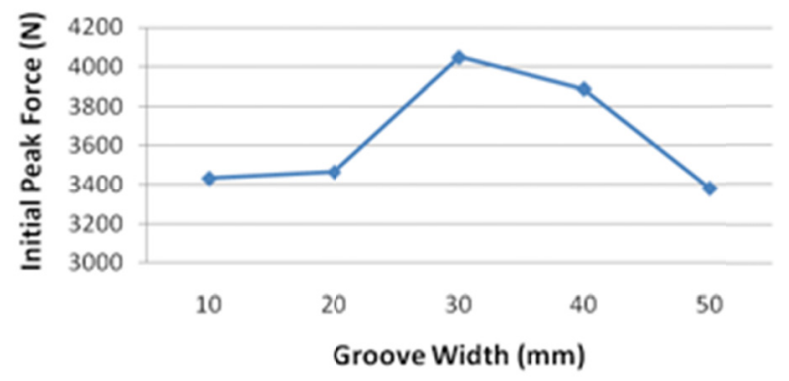

Figure 21. Initial peak force of 1-grooved SHS column with different groove widths and at impact speed of $14 \mathrm{~m} / \mathrm{s}$ and impact mass of $5 \mathrm{~kg}$ 


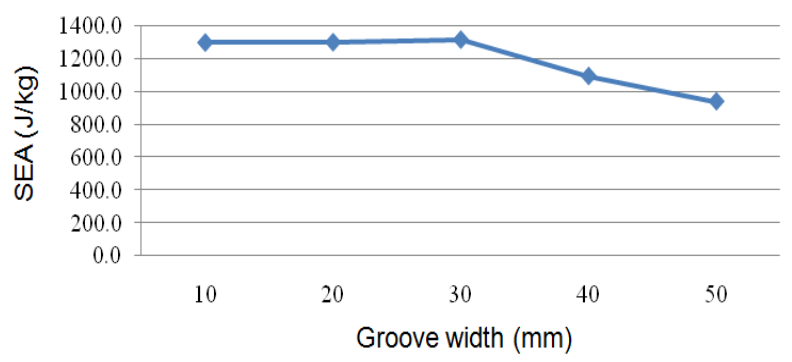

Figure 22. Specific energy absorption (SEA) of 1-grooved SHS column with different groove widths and at impact speed of $14 \mathrm{~m} / \mathrm{s}$ and impact mass of $5 \mathrm{~kg}$

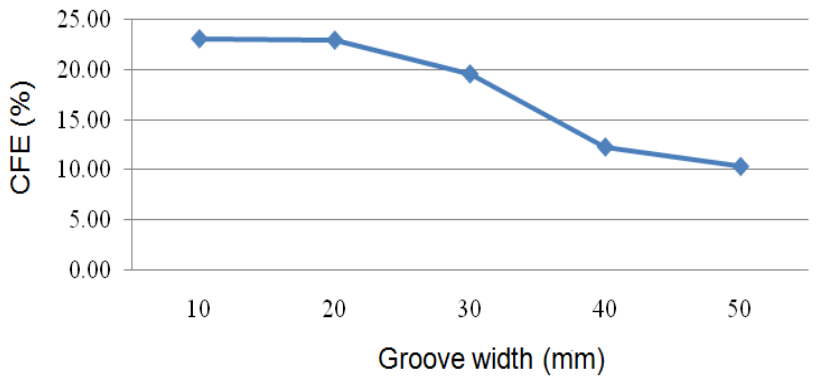

Figure 23. Crush force efficiency (CFE) of 1-grooved SHS column with different groove widths and at impact speed of $14 \mathrm{~m} / \mathrm{s}$ and impact mass of $5 \mathrm{~kg}$

\subsection{Effect of Spacing on 2-Grooved SHS Column With Thickness of $1 \mathrm{~mm}$, Groove Depth of $6 \mathrm{~mm}$ and Groove} Width of $10 \mathrm{~mm}$

Figure 24 shows the force-displacement curves of the 2-grooved columns with different spacing distances. It can be seen that columns with smaller spacings exhibited more favourable impact response with low IPF and shorter crushing distances. Spacings of $15 \mathrm{~mm}$ and greater resulted in higher peak forces and longer crushing distances. Columns with bigger spacings tended to exhibit gradual decrease in mean forces after crushing distance of about $0.125 \mathrm{~m}$. Figure 25 shows the deformed shapes of the 2-grooved SHS columns with different spacings. Columns with spacings of $5 \mathrm{~mm}$ and $10 \mathrm{~mm}$ show flatening of the grooves and moderate folding of the sides. Columns with bigger spacings exhibit prominent folding of the sides and top face. The flatening of the grooves for the columns with smaller spacings dissipates the impact energy, hence reducing the folding of the sides and bending of the columns.

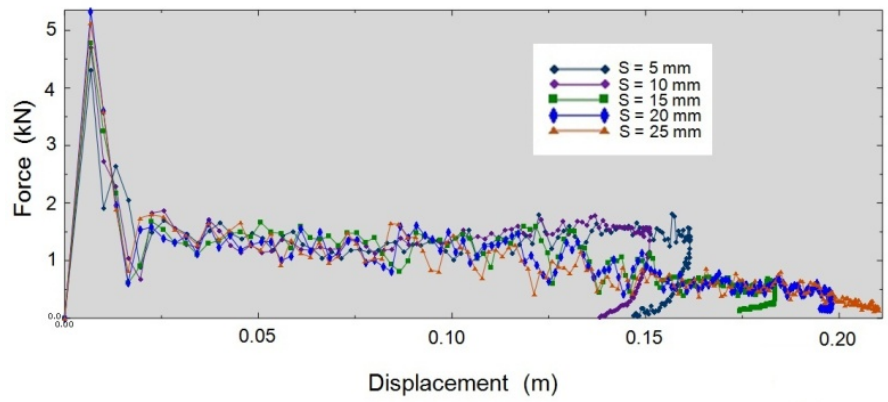

Figure 24. Force-displacement curves of 2-grooved SHS column with impact speed of $14 \mathrm{~m} / \mathrm{s}$ and impact mass of $5 \mathrm{~kg}$ and different spacing 

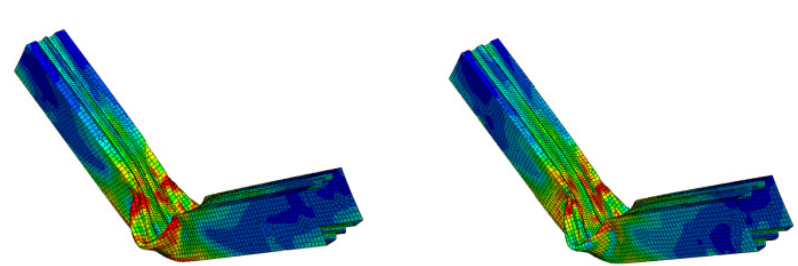

$\mathrm{s}=5 \mathrm{~mm}$

$\mathrm{s}=10 \mathrm{~mm}$
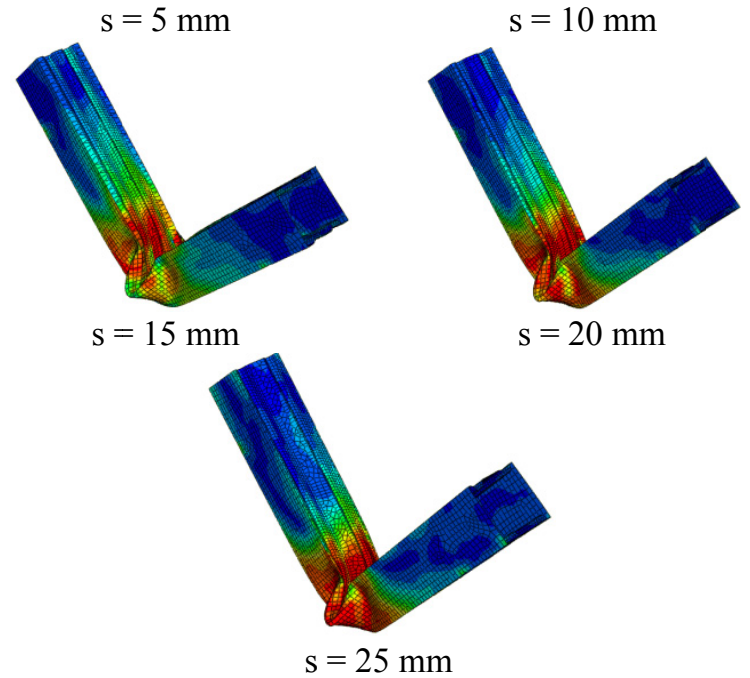

Figure 25. Deformed shapes of 2-grooved SHS column with impact speed of $14 \mathrm{~m} / \mathrm{s}$ and impact mass of $5 \mathrm{~kg}$

Figure 26 shows that the IPFs of the 2-grooved columns gradually increased with increased spacing. Spacing of 5 $\mathrm{mm}$ gave the lowest IPF while spacing of $20 \mathrm{~mm}$ gave the highest. Figure 27 shows that spacing of $5 \mathrm{~mm}$ and 10 $\mathrm{mm}$ have similar SEA. For spacing of $15 \mathrm{~mm}$, there was a substantial reduction of SEA. Further increasing the spacing to $20 \mathrm{~mm}$ and $25 \mathrm{~mm}$ had minimal effect on the SEA. Figure 28 shows that the CFE of the 2-grooved columns gradually decreased with increased spacing. The results suggested that groove spacing of $5 \mathrm{~mm}$ would be the best design as it has the lowest IPF, highest SEA and CFE.

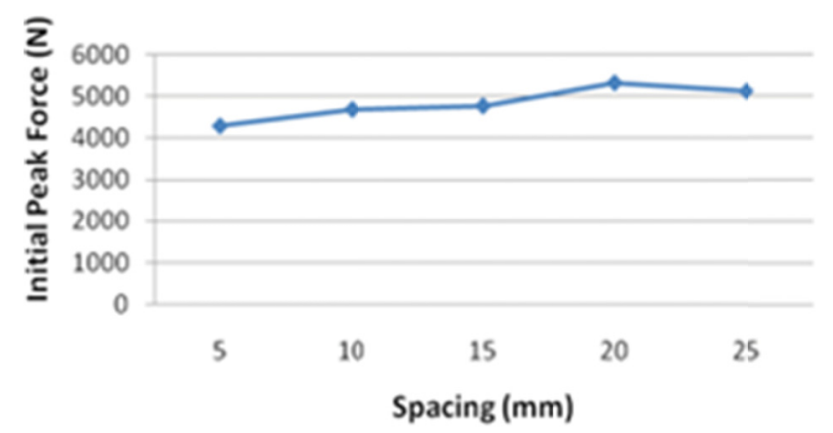

Figure 26. Initial peak force of 2-grooved SHS column with different spacing at impact speed of $14 \mathrm{~m} / \mathrm{s}$ and impact mass of $5 \mathrm{~kg}$

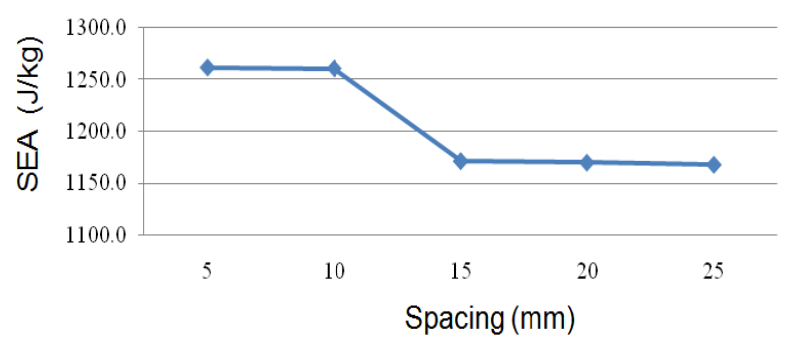

Figure 27. Specific energy absorption (SEA) of 2-grooved SHS column with different spacing at impact speed of $14 \mathrm{~m} / \mathrm{s}$ and impact mass of $5 \mathrm{~kg}$ 


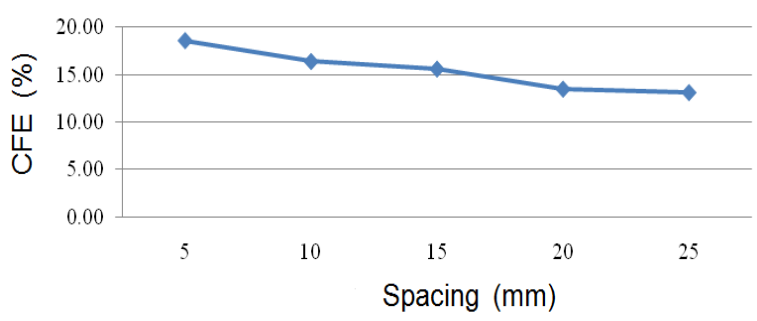

Figure 28. Crush force efficiency (CFE) of 2-grooved SHS column with different spacing at impact speed of 14 $\mathrm{m} / \mathrm{s}$ and impact mass of $5 \mathrm{~kg}$

\section{Conclusions}

The study has shown that width, depth and spacing of the groove have considerable effect on the impact response, initial peak force, SEA and CFE of the grooved SHS column. Overall, single groove column with groove width of $25 \mathrm{~mm}$, groove depth of $3 \mathrm{~mm}$ and thickness of $1 \mathrm{~mm}$ gave the best IPF, SEA and CFE. This is an important feature when designing for side impact protection where impact energy need to be efficiently absorbed at the shortest possible distance.

This work demonstrates the possibilities of modifying the structure impact energy absorption characteristics by the addition of grooves of various sizes on the selected faces of the structure. It is believed that the structure impact performance can be improved by using this method.

\section{References}

Cheon, S. S., Lee, D. G., \& Jeong, K. S. (1997). Composite side-door impact beams for passenger cars. Composite Structure, 38(1), 229-239. http://dx.doi.org/10.1016/S0263-8223(97)00058-5

Farley, G. L., \& Jones, R. M. (1992). Prediction of The energy absorption capability of composite tubes. Journal of Composite Material, 26(3), 388-404. http://dx.doi.org/10.1177/002199839202600304

Galib, D. A., \& Limam, A. (2004). Experimental and numerical investigation of static and dynamic axial crushing of circular aluminum tubes. URGC Structure, INSA de Lyon, Villeurbanne, France.

Kecman, D. (1983). Bending collapse of rectangular and square section tubes. Int. J. Mech. Sciences, 25, 623- 638. http://dx.doi.org/10.1016/0020-7403(83)90072-3

Md Fuad, S. K., Ahmad Mujahid, A. Z., Mohd Zaid, O., Shohaimi, A., \& Suresh, T. (2013). The Effect of Mesh Sizing Toward Deformation Result in Computational Dynamic Simulation for Blast Loading Application. Modern Applied Science, 7(7), 23-29. http://dx.doi.org/10.5539/mas.v7n7p23

Santosa, S., Banhart, J., \& Wierzbicki, T. (2001). Experimental and numerical analysis of bending of foam-filled sections. Acta Mech, 48,199-213. http://dx.doi.org/10.1007/BF01183678

Yu, T. X., \& Lu, G. (2003). Energy absorption of structures and materials. Cambridge, United Kingdom: Woodhead Publishing.

Zarei, H. R., \& Kröger, M. (2008). Bending behavior and foam-filled beams: Structural Optimization. International Journal of Impact Engineering, 35, 521-529. http://dx.doi.org/10.1016/j.ijimpeng.2007.05.003

\section{Copyrights}

Copyright for this article is retained by the author(s), with first publication rights granted to the journal.

This is an open-access article distributed under the terms and conditions of the Creative Commons Attribution license (http://creativecommons.org/licenses/by/3.0/). 